\title{
Correction to: Effects of long-term straw incorporation on lignin accumulation and its association with bacterial laccase-like genes in arable soils
}

\author{
Shuzhen Feng ${ }^{1,2,3} \cdot$ Yirong $\mathrm{Su}^{1,3} \cdot$ Xunyang $\mathrm{He}^{1,3} \cdot$ Yajun $\mathrm{Hu}^{1,3} \cdot$ Zhenhua Zhang ${ }^{4} \cdot$ Hongbo He $^{5} \cdot$ Khalil Kariman $^{6}$. \\ Jinshui $\mathrm{Wu}^{1} \cdot$ Xiangbi Chen ${ }^{1,3}$
}

Published online: 8 March 2019

(C) Springer-Verlag GmbH Germany, part of Springer Nature 2019

\section{Correction to: Appl Microbiol Biotechnol (2019) 103:1961-1972 https://doi.org/10.1007/s00253-018-9563-7}

There is an error in the Original Publication of this paper about the incorrect funding number.

The first funding No. should be $\mathbf{4 1 6 7 1 2 9 8}$ instead of 41301298.

Publisher's note Springer Nature remains neutral with regard to jurisdictional claims in published maps and institutional affiliations.

The online version of the original article can be found at https://doi.org/ 10.1007/s00253-018-9563-7

Xiangbi Chen

xbchen@isa.ac.cn

1 Key Laboratory of Agro-ecological Processes in Subtropical Region, Institute of Subtropical Agriculture, the Chinese Academy of Sciences, Changsha 410125, People's Republic of China

2 Guangxi University of Science and Technology, Liuzhou 545006, People's Republic of China

3 Huanjiang Observation and Research Station for Karst Ecosystems, Huanjiang 547100, People's Republic of China

4 Southern Regional Collaborative Innovation Center for Grain and Oil Crops in China, Hunan Agricultural University, Changsha 410128, People's Republic of China

5 Key Laboratory of Terrestrial Ecological Process, Institute of Applied Ecology, The Chinese Academy of Sciences, Shenyang 110016, People's Republic of China

6 School of Agriculture and Environment, The University of Western Australia, Crawley, WA 6009, Australia 